\title{
Comparison of the Canadian CT head rule and the new orleans criteria in patients with minor head injury
}

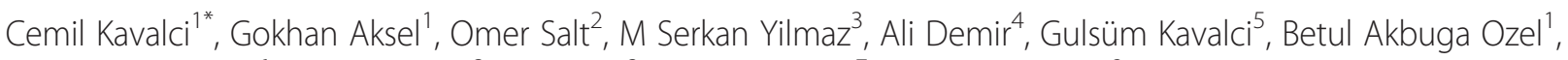
Ertugrul Altinbilek ${ }^{6}$, Tamer Durdu ${ }^{3}$, Cihat Yel $^{3}$, Polat Durukan ${ }^{7}$ and Bahattin Isik ${ }^{8}$

\begin{abstract}
Aim: The aim of the study was to compare the New Orleans Criteria and the New Orleans Criteria according to their diagnostic performance in patients with mild head injury.

Methods: The study was designed and conducted prospectively after obtaining ethics committee approval. Data was collected prospectively for patients presenting to the ED with Minor Head Injury. After clinical assessment, a standard CT scan of the head was performed in patients having at least one of the risk factors stated in one of the two clinical decision rules.

Patients with positive traumatic head injury according to BT results defined as Group 1 and those who had no intracranial injury defined as Group 2. Statistical analysis was performed with SPSS 11.00 for Windows. ROC analyze was performed to determine the effectiveness of detecting intracranial injury with both decision rules. $p<0.05$ was considered statistically significant.
\end{abstract}

Results: 175 patients enrolled the study. Male to female ratio was 1.5. The mean age of the patients was $45 \pm 21,3$ in group 1 and $49 \pm 20,6$ in group 2 . The most common mechanism of trauma was falling. The sensitivity and specificity of CCHR were respectively $76.4 \%$ and $41.7 \%$, whereas sensitivity and specificity of NOC were $88.2 \%$ and $6.9 \%$.

Conclusion: The CCHR has higher specificity, PPV and NPV for important clinical outcomes than does the NOC.

Keywords: Emergency, Head injury, CT rules

\section{Introduction}

Minor head injury (MHI) is one of the most common injury type seen in the emergency departments (ED) [1]. The average incidence of MHI is reported to be 503.1/ 100000 , with peaks among males and those $<5$ years of age [2]. No universally agreed definition of MHI exists. Some authors define MHI as the blunt injury of the head with alteration in consciousness, amnesia, or disorientation in a patient who has a Glasgow Coma Scale (GCS) score of 13 to 15 [3,4], although others define it as the blunt injury of the head with alteration in consciousness, amnesia, or disorientation in a patient who has a Glasgow Coma Scale (GCS) score of 14 to 15 [5]. The key to managing these patients is early diagnosis of intracranial injuries using

\footnotetext{
* Correspondence: cemkavalci@yahoo.com

${ }^{1}$ Emergency Department, Baskent University Faculty of Medicine, Ankara, Turkey Full list of author information is available at the end of the article
}

computed tomography $(\mathrm{CT})$ [6,7]. CT is widely accepted as an effective diagnostic modality to detect rare but clinically significant intracranial injuries in patients suffering minor head injury [8]. As such, it has been increasingly utilized as a routine test for these patients [9]. Systematic evaluation by CT scan would not be a cost-effective strategy in mild head injury because potentially life-threatening complications that may require neurosurgical intervention occur in less than $1 \%$ of cases [4]. In addition, some reports warn against its harmful effects (particularly for children) due to the radiation exposure [10]. Yet, CT use is growing rapidly, potentially exposing patients to unnecessary ionizing radiation risk and costs [11].

Commonly accepted clinical decision rules for detecting life-threatening complications in patients with mild head injury are New Orleans Criteria (NOC) and the Canadian CT Head Rules (CCHR) [3,4,12]. These two rules were 
Table 1 Canadian CT head rule and New Orleans Criteria

\begin{tabular}{ll}
\hline Canadian CT Head Rule High risk (for neurosurgical interventions) & New Orleans Criteria \\
\hline - GCS score, 15 at two hours after injury & • Headache \\
- Suspected open or depressed skull fracture & • Vomiting \\
- Any sign of basal skull fracture (hemotympanum, & • Older than 60 years \\
"panda" eyes, cerebrospinal fluid otorrhoea, Battle's sign). & \\
- Vomiting more than once & • Drug or alcohol intoxication \\
- Age $>65$ years & • Persistent anterograde amnesia (deficits in short-term memory) \\
Medium risk (for brain injury on CT) & • Visible trauma above the clavicle \\
- Persistent retrograde amnesia of greater than 30 minutes & - Seizure \\
\hline - Dangerous mechanism of injury (pedestrian struck by vehicle, \\
\hline
\end{tabular}

externally validated in the previous studies but we believe that application of these decision rules may still be limited in populations with different demographic and epidemiologic features. The aim of the study was to compare the CCHR and the NOC according to their diagnostic performance in $\mathrm{MHI}$ patients.

\section{Materials and methods}

This study was conducted at a single tertiary care center in Turkey with an annual ED census of 70,000 visits. The study was designed and conducted prospectively after ethics committee approval. Acute MHI was defined as a patient having a blunt trauma to the head within 24 hours, with a Glasgow Coma Scale (GCS) score of 13 to 15 . The patients were also required to have at least one of the risk factors stated in CCHR or NOC (Table 1).

Table 2 Characteristics of patients

\begin{tabular}{|c|c|c|c|}
\hline & Group 1 & Group 2 & $P$ value \\
\hline Sex (male/female) & $14 / 3$ & $92 / 66$ & $p>0,05$ \\
\hline Age $\left(\right.$ mean $\left.\pm s d^{*}\right)$ & $45 \pm 21,3$ & $49.57 \pm 20,6$ & $p>0,05$ \\
\hline \multicolumn{4}{|l|}{ Trauma mechanism } \\
\hline Motor vehicle accident & 2 & 34 & \\
\hline Pedestrian & 0 & 8 & $p>0,05$ \\
\hline Falling & 8 & 68 & \\
\hline Assault & 7 & 48 & \\
\hline \multicolumn{4}{|l|}{ Symptom } \\
\hline Headache & 12 & 139 & \\
\hline Amnesia & 1 & 7 & \\
\hline Vomiting & 2 & 19 & \\
\hline Lethargy & 3 & 6 & \\
\hline Loss of consciousness & 1 & 9 & \\
\hline \multicolumn{4}{|l|}{ GCS } \\
\hline 13 & 3 & 4 & \\
\hline 14 & 0 & 9 & \\
\hline 15 & 14 & 145 & \\
\hline
\end{tabular}

*Sd=standart deviation, GCS=Glasgow Coma Scale Score.
Patients with GCS score of less than 13 or instable vital signs, presentation time more than 24 hours after head trauma, patients with an obvious penetrating skull injury or obvious depressed fracture, presence of major trauma, bleeding disorder or use of oral anticoagulants (e.g., warfarin), contraindications for $\mathrm{CT}$ and those pregnant or fewer than 18 were excluded from the study.

All patients were assessed by an emergency physician or by supervised emergency medicine residents. Data collection was done prospectively using a data collection sheet. After clinical assessment, a standard CT scan of the head was performed in patients having at least one of the risk factors stated in one of the two clinical decision rules. The $\mathrm{CT}$ scans were interpreted by a radiologist who was blinded to patient data. Presence of traumatic lesions on head CT scan was the main outcome. The lesions accepted as positive CT results for the study were subarachnoid hemorrhage, epidural hemorrhage, subdural hematoma, intraparenchymal hematoma, compression fracture, cerebral edema and contusion.

Cases without a complete data sheet were excluded. Demographic characteristics, mechanism of injury, traumatic findings at CT were all evaluated. CCHR and NOC were also assessed in patients who presented with a minor head trauma. Patients with positive traumatic head injury according to BT results defined as Group 1 and those who had no intracranial injury defined as Group 2. Statistical

Table 3 Computed tomography results of the patients

\begin{tabular}{lll}
\hline BT results & N & \% \\
\hline Normal & 156 & 89.1 \\
Epidural hemorrhage & 3 & 1.8 \\
Depressed fracture & 2 & 1.2 \\
Cerebral edema & 4 & 2.4 \\
Subdural hematoma & 3 & 1.8 \\
Intraparenchymal hematoma & 1 & 0.6 \\
Subarachnoid hemorrhage & 6 & 3.4 \\
Contusion & 2 & 1.2 \\
\hline
\end{tabular}


Table 4 Rates of patients meet the criteria according to groups for patients with GCS 13

\begin{tabular}{lcc}
\hline Predictor & Group 1 & Group 2 \\
\hline Canadian $C^{*}$ Head Rule & & \\
Positive & 3 & 0 \\
Negative & 4 & \\
New Orleans Criteria & & 0 \\
Positive & 3 & 0 \\
Negative & 4 & \\
\hline
\end{tabular}

analysis was performed with SPSS (version 11.0; SPSS, Inc., Chicago, IL). Results were expressed with number and percentage. Chi-square test was used in comparison of categorical data. ROC analyze was performed to determine the effectiveness of detecting intracranial injury with both decision rules. The sensitivity, specificity, and predictive values with $95 \%$ confidence intervals (CIs) for performance of each decision rule for CT scan intracranial traumatic findings were calculated separately for patients having GCS score of 13 and patients having GCS score of 14-15. P $<0.05$ was considered statistically significant. When appropriate, CIs were calculated with a 95\% confidence level.

\section{Results}

During the study period, data were collected for 198 trauma patients who met inclusion criteria. Of these, 21 were excluded because of refusing to be included in the study, 2 were excluded because of missing data, resulting in 175 patients in the data analysis. Table 2 shows the demographic and clinical characteristics of the overall study group. In the enrolled patients, male to female ratio was 1.5 . The mean age of the patients was $45 \pm 21.3$ in group 1 and $49 \pm 20.6$ in group 2. The most common mechanism of trauma was falling. Headache was the main symptom in both groups (Table 2). CT scan was performed in all of 175 patients; pathologic findings were present in 17 patients $(9.71 \%)$. The most common intracranial injury was Subarachnoid hemorrhage (Table 3).

Sensitivity, Specificity, PPV, and NPV of both of the criteria of the patients having GCS score 13 were $100 \%$, \% $42 \%$ and $100 \%$ respectively (Table 4 , Figure 1 ).

For the patients having GCS score between 14-15; the sensitivity and specificity of CCHR were $78.5 \%$ and $42.8 \%$ respectively, whereas sensitivity and specificity of NOC were $85.7 \%$ and $0.7 \%$. Positive predictive value (PPV) and negative predictive value (NPV) were both higher in CCHR than NOC. PPV and NPV of CCHR were respectively $11.1 \%$ and $95.6 \%$ whereas PPV and NPV of NOC were $0.7 \%$ and $84.6 \%$ (Table 5, Figure 2).

\section{Discussion}

In the most of the prior studies, motor vehicle accidents were reported to be the most common mechanism of trauma $[3,4]$. Some other authors also reported the

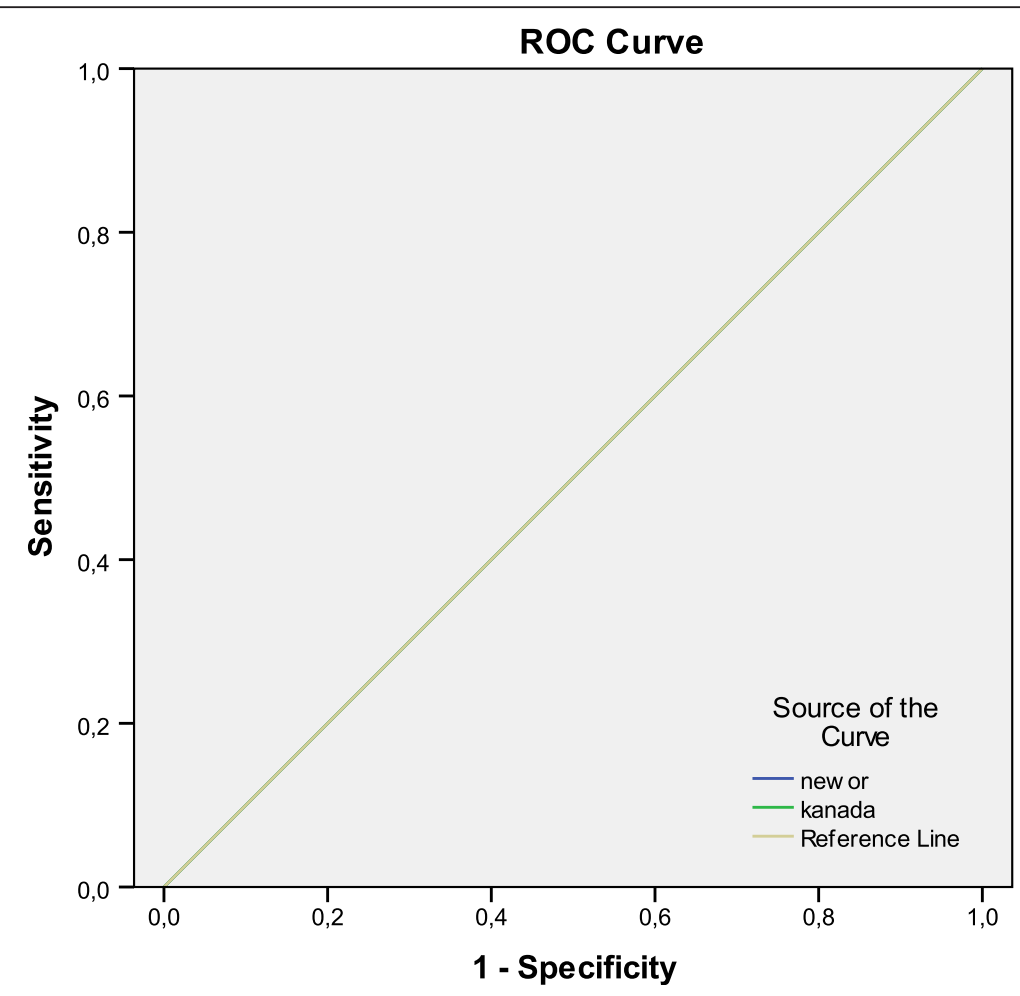

Figure 1 Ratio of detecting intracranial injury of decision rules for patients with GCS 13. Diagonal segments are produced by ties. 
Table 5 Rates of patients meet the criteria according to groups for patients with GCS 14-15

\begin{tabular}{lcc}
\hline Predictor & Group 1 & Group 2 \\
\hline Canadian CT* Head Rule & 11 & 88 \\
Positive & 3 & 66 \\
Negative & & \\
New Orleans Criteria & 12 & 143 \\
Positive & 2 & 11 \\
Negative & & \\
\hline
\end{tabular}

${ }^{*} \mathrm{CT}=$ Computed tomography.

falling as the most common trauma mechanism [13]. In the present study, the most common mechanism for trauma was found as falling in accordance with the later study. Assault was the second and motor vehicle accidents were the third most common mechanisms of trauma. Our hospital is in the center of the city, and away from the high ways. This may be the reason for motor vehicle accidents to be the third most common cause. The mechanism of trauma is probably depends on the distance from hospital to high ways, social and economical status and degree or level of hospital as trauma centre. Similar to prior studies, males were the most affected sex group from the trauma in the present study $[3,4,13]$. This is probably due to men's working in more dangerous jobs, taking more places in active city social life, being more associated with violence and male drivers being more than females.

In the present study, efficacy of both criteria were found similar in the patients having GCS score 13. In the patients having GCS score 14-15, a comparison of the clinical decision rules for use of CT in patients with MHI showed that both the CCHR and the NOC were sensitive for the outcome measure of any traumatic intracranial lesion on CT which is "clinically important" brain lesion. Although the sensitivity was high in these two decision rules, they both had much lower sensitivities in this study than the original published studies [3,13-15]. Papa et al. and Smits et al. found sensitivities of both rules to reach $100 \%[13,15]$. The cause of lower sensitivities may be explained by our patients' low socioeconomic status and unreliable history. In contrast to previous publications, Ro et al. found lower sensitivities in both decision rules similar to our study results. They also found the sensitivity higher in NOC and specificity higher in CCHR [16]. In the present study, the specificity of CCHR was higher than specificity of NOC $(47,1 \%$ versus $6.9 \%)$. Our results were similar to the results of the study reported by Smits et al. They found the specificity of CCHR higher than the specificity of NOC $(39.7 \%$ versus 5.6\%) [13]. Papa et al. and Stiell et al. also found the specificity of CCHR higher than NOC $[3,15]$. In the present study, CCHR was found to be superior to NOC

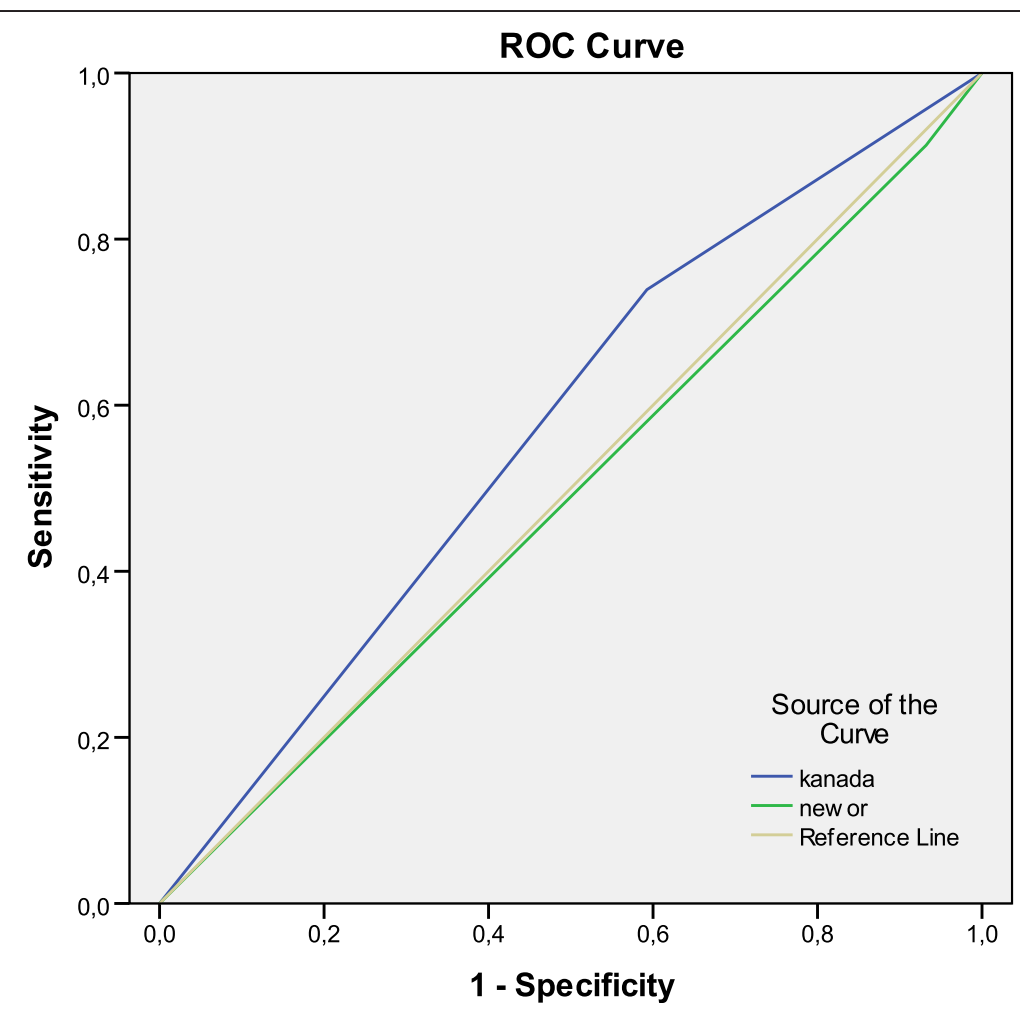

Figure 2 Ratio of detecting intracranial injury of decision rules for patients with GCS 14-15. Diagonal segments are produced by ties. 
due to higher specificity, higher PPV and NPV. The only superiority of NOC in our study was the sensitivity with $88.2 \%$ while it was $76.4 \%$ in CCHR. Many prior studies also found the sensitivity of NOC higher than the sensitivity of CCHR $[13,16]$. Smits et al. tried to explain this difference in sensitivities for neurocranial traumatic CT findings between the 2 decision rules with more stringent use of the risk factor of external injury in the CCHR. For example in the NOC, this risk factor comprises all external injuries above the clavicles. Despite the NOC having higher sensitivity, specificities for neurocranial traumatic CT findings were low for the NOC decision rule, and higher for the CCHR [13]. In accordance with Smits et al. higher sensitivity of NOC causes the lower specificity and this means an increase in healthcare costs.

\section{Conclusion}

In summary, for patients with $\mathrm{MHI}$, the CCHR and the NOC have both high sensitivities for clinically important brain injury although this study reports much lower sensitivities than the prior published studies. Additionally, the CCHR has higher specificity, PPV and NPV for important clinical outcomes than does the NOC. We believe that use of CCHR may result in reduced imaging rates, reduced costs and this would help us to protect our patients from the side effects of radiation.

\section{Limitations}

This study is conducted in one center. A multicenter study having larger number of patients and more trauma patients caused by much different mechanism could have been assessed. The study focused only on the two widely accepted clinical decision rules but did not study on other decision rules or aspects.

Our primary outcome measure was any traumatic neurocranial lesions on the CT scan. The third limitation of this study is absence of the second outcome measure which can be defined as findings on the CT scan that led to neurosurgical intervention.

\section{Competing interests}

The authors declare that they have no competing interests.

\section{Authors' contributions}

The quantitative analysis was planned by CK, MSY, AD. Study data were analyzed by $C K, C Y, G K$ and interpreted by BAO, TD, EA, PD. The first version of the manuscript was drafted by AD, GA, BI. All authors contributed to the edition and revision of the manuscript and the final version of the article was reviewed and approved by all authors.

\section{Author details}

'Emergency Department, Baskent University Faculty of Medicine, Ankara, Turkey. 2Emergency Department, State hospital, Yozgat, Turkey. ${ }^{3}$ Emergency Department, Numune Training and Research Hospital, Ankara, Turkey. ${ }^{4}$ Emergency Department, Yenimahalle State hospital, Ankara, Turkey. ${ }^{5}$ Anesthesia Department, Yenimahalle State hospital, Ankara, Turkey. ${ }^{6}$ Emergency Department, Şişli Hamidiye Etfal Training and Research Hospital, Istanbul, Turkey. ${ }^{7}$ Emergency Department, Erciyes University Faculty of Medicine, Kayseri, Turkey. ${ }^{8}$ Emergency Department, Keciören Training and Research Hospital, Ankara, Turkey.
Received: 21 February 2014 Accepted: 10 April 2014

Published: 17 April 2014

\section{References}

1. Cassidy JD, Carroll L, Peloso PM, Borg J, Von Holst H, Holm L, Kraus J, Coronado VG: Incidence, risk factors and prevention of mild traumatic brain injury: results of the WHO Collaborating Centre Task Force on Mild Traumatic Brain Injury. Collaborating Centre Task Force on Mild Traumatic Brain Injury. J Rehabil Med 2004, 43:28-60.

2. Bazarian JJ, McClung J, Shah MN, Cheng YT, Flesher W, Kraus J: Mild traumatic brain injury in the United States, 1998-2000. Brain Inj 2005, 19(2):85-91.

3. Stiell IG, Clement CM, Rowe BH, Schull MJ, Brison R, Cass D, Eisenhauer MA, McKnight RD, Bandiera G, Holroyd B, Lee JS, Dreyer J, Worthington JR, Reardon M, Greenberg G, Lesiuk H, MacPhail I, Wells GA: Comparison of the Canadian CT Head Rule and the New Orleans Criteria in patients with minor head injury. JAMA 2005, 294(12):1511-1518.

4. Bouida W, Marghli S, Souissi S, Ksibi H, Methammem M, Haguiga H, Khedher S, Boubaker H, Beltaief K, Grissa MH, Trimech MN, Kerkeni W, Chebili N, Halila I, Rejeb I, Boukef R, Rekik N, Bouhaja B, Letaief M, Nouira S: Prediction value of the Canadian CT head rule and the New Orleans criteria for positive head CT scan and acute neurosurgical procedures in minor head trauma: a multicenter external validation study. Ann Emerg Med 2013, 61(5):521-527.

5. Hung RH: Minor Head Injury in Infants and Children. In Tintinalli's Emergency Medicine. 7th edition. Edited by Tintinalli JE. New York: Mc Graw- Hill; 2011:888-892.

6. Shackford SR, Wald SL, Ross SE, Cogbill TH, Hoyt DB, Morris JA, Mucha PA, Pachter HL, Sugerman HJ, O'Malley K: The clinical utility of computed tomographic scanning and neurologic examination in the management of patients with minor head injuries. J Trauma 1992, 33(3):385-394.

7. Stein SC, Ross SE: The value of computed tomographic scans in patients with low-risk head injuries. Neurosurgery 1990, 26(4):638-640.

8. Klement W, Wilk S, Michalowski W, Farion KJ, Osmond MH, Verter V: Predicting the need for $\mathrm{CT}$ imaging in children with minor head injury using an ensemble of Naive Bayes classifiers. Artif Intell Med 2012, 54(3):163-170.

9. Smits M, Dippel DW, Nederkoorn PJ, Dekker HM, Vos PE, Kool DR: Minor head injury: CT-based strategies for management-a cost-effectiveness analysis. Radiology 2010, 254(2):532-540.

10. Brenner DJ, Hall EJ: Computed tomography - an increasing source of radiation exposure. N Engl J Med 2007, 357(22):2277-2284.

11. Melnick ER, Szlezak CM, Bentley SK, Dziura JD, Kotlyar S, Post LA: CT overuse for mild traumatic brain injury. Jt Comm J Qual Patient Saf 2012, 38(11):483-489.

12. Stiell IG, Wells GA, Vandemheen $\mathrm{K}$, Clement C, Lesiuk H, Laupacis A: The Canadian CT Head Rule for patients with minor head injury. Lancet 2001, 357(9266):1391-1396.

13. Ro YS, Shin SD, Holmes JF, Song KJ, Park JO, Cho JS, Lee SC, Kim SC, Hong KJ, Park CB, Cha WC, Lee EJ, Kim YJ, Ahn KO, Ong ME: Comparison of clinical performance of cranial computed tomography rules in patients with minor head injury: a multicenter prospective study. Acad Emerg Med 2011, 18(6):597-604.

14. Smits M, Dippel DW, De Haan GG, Dekker HM, Vos PE, Kool DR, Nederkoorn PJ, Hofman PA, Twijnstra A, Tanghe HL, Hunink MG: External validation of the Canadian CT Head Rule and the New Orleans Criteria for CT scanning in patients with minor head injury. JAMA 2005, 294(12):1519-1525.

15. Stein SC, Fabbri A, Servadei F, Glick HA: A critical comparison of clinical decision instruments for computed tomographic scanning in mild closed traumatic brain injury in adolescents and adults. Ann Emerg Med 2009, 53(2):180-188.

16. Papa L, Stiell IG, Clement CM, Pawlowicz A, Wolfram A, Braga C, Draviam S, Wells GA: Performance of the Canadian CT Head Rule and the New Orleans Criteria for predicting any traumatic intracranial injury on computed tomography in a United States Level I trauma center. Acad Emerg Med 2012, 19(1):2-10.

doi:10.1186/1749-7922-9-31

Cite this article as: Kavalci et al: Comparison of the Canadian CT head rule and the new orleans criteria in patients with minor head injury. World Journal of Emergency Surgery 2014 9:31. 